\title{
Consensus clinical management guidelines for Niemann-Pick disease type C
}

\author{
Tarekegn Geberhiwot ${ }^{{ }^{*}}$ (D), Alessandro Moro ${ }^{2}$, Andrea Dardis², Uma Ramaswami ${ }^{3}$, Sandra Sirrs ${ }^{4}$, \\ Mercedes Pineda Marfa ${ }^{5}$, Marie T. Vanier ${ }^{6}$, Mark Walterfang ${ }^{7}$, Shaun Bolton ${ }^{8}$, Charlotte Dawson ${ }^{8}$, Bénédicte Héron ${ }^{9}$, \\ Miriam Stampfer ${ }^{10}$, Jackie Imrie ${ }^{11}$, Christian Hendriksz ${ }^{12}$, Paul Gissen ${ }^{13}$, Ellen Crushell ${ }^{14}$, Maria J. Coll ${ }^{15}$, \\ Yann Nadjar ${ }^{16}$, Hans Klünemann ${ }^{17}$, Eugen Mengel ${ }^{18}$, Martin Hrebicek ${ }^{19}$, Simon A. Jones ${ }^{20}$, Daniel Ory ${ }^{21}$, \\ Bruno Bembi ${ }^{2}$, Marc Patterson ${ }^{22}$ and on behalf of the International Niemann-Pick Disease Registry (INPDR)
}

\begin{abstract}
Niemann-Pick Type C (NPC) is a progressive and life limiting autosomal recessive disorder caused by mutations in either the NPC1 or NPC2 gene. Mutations in these genes are associated with abnormal endosomal-lysosomal trafficking, resulting in the accumulation of multiple tissue specific lipids in the lysosomes. The clinical spectrum of NPC disease ranges from a neonatal rapidly progressive fatal disorder to an adult-onset chronic neurodegenerative disease. The age of onset of the first (beyond 3 months of life) neurological symptom may predict the severity of the disease and determines life expectancy.

NPC has an estimated incidence of $\sim 1: 100,000$ and the rarity of the disease translate into misdiagnosis, delayed diagnosis and barriers to good care. For these reasons, we have developed clinical guidelines that define standard of care for NPC patients, foster shared care arrangements between expert centres and family physicians, and empower patients. The information contained in these guidelines was obtained through a systematic review of the literature and the experiences of the authors in their care of patients with NPC. We adopted the Appraisal of Guidelines for Research \& Evaluation (AGREE II) system as method of choice for the guideline development process. We made a series of conclusive statements and scored them according to level of evidence, strengths of recommendations and expert opinions. These guidelines can inform care providers, care funders, patients and their carers of best practice of care for patients with NPC. In addition, these guidelines have identified gaps in the knowledge that must be filled by future research. It is anticipated that the implementation of these guidelines will lead to a step change in the quality of care for patients with NPC irrespective of their geographical location.
\end{abstract}

Keywords: Niemann-Pick Type C, NPC, Guidelines, Diagnosis, Management

\section{Background}

Niemann-Pick Type C (NPC) disease is a rare genetic disease whose clinical spectrum ranges from a fatal antenatal disorder to an adult-onset chronic neurodegenerative disease. The rarity of the disease and the scarcity of expertise translate into misdiagnosis, delayed diagnosis and barriers to adequate care. This results in additional physical, psychological and intellectual impairments, inadequate or inappropriate treatment, loss of confidence in the healthcare system, and patient disempowerment,

\footnotetext{
* Correspondence: tarekegn.hiwot@uhb.nhs.uk

${ }^{1}$ Institute of Metabolism and System Research, University of Birmingham,

Birmingham, UK

Full list of author information is available at the end of the article
}

even though the diagnosis of NPC is compatible with improved quality of life if a diagnosis is made promptly and appropriate comprehensive management is instituted. There is as yet no disease-specific curative therapy available, and the disease usually progresses to premature death. The mainstay of management is symptomatic supportive therapy using multidisciplinary and multiprofessional teams of experts. Some countries have national standard operating procedures to improve the care of NPC patients, but the NPC community, represented by the International Niemann-Pick disease Alliance (INPDA), has not previously initiated the development of a comprehensive disease management guidelines to provide a resource for the multidisciplinary 
team, and to support patients and their primary professional caregivers on the current diagnosis, treatment, monitoring and outcome measures for patients with NPC. This document represents general guidelines, which in the opinion of the authors can inform care providers about the needs of patients with NPC in order to provide equitable and improved care, define standard of care for NPC patients, foster shared care arrangements between expert centres and family physicians, and empower patients. The guidelines refer to the management of patients suspected or diagnosed with NPC disease at any age. These guidelines should be of value to: a) specialist centres, other hospital-based medical teams and other staff involved with the care of NPC disease patients, b) family physicians and other primary caregivers and c) patients and their families. The guidelines have been developed by experts with extensive experience of European, Australian and North American healthcare systems and populations. However, they might equally be applicable to any country that operates similar healthcare services. It is anticipated that implementation of these guidelines will lead to a step change in the quality of care for patients with NPC.

\section{Methods}

These guidelines have been developed by expert physicians, geneticists, allied healthcare professionals and patient support groups involved in the International Niemann-Pick Disease Registry (INPDR) project (www. inpdr.org), which is supported by the EU Directorate General for Health and Consumers (DG-SANCO) via the Consumers, Health, Agriculture and Food Executive Agency (CHAFEA). The INPDR consortium comprises 27 partners from 13 countries in Europe, Australia, Canada and the United States of America. One of the goals of the INPDR is to support equitable care of Niemann-Pick disease patients by standardizing the quality of care all patients receive. In addition, the European Metabolic Reference network (MetabERN) has adopted this guideline for the management of NPC patients within the network.

The Guidelines Development Group (GDG) consisted of expert representatives from a range of professional groups including paediatric and adult neurologists, paediatric and adult metabolic specialists, psychiatrists, epidemiologists, clinical biochemists, geneticists, specialist metabolic dieticians, physiotherapists, psychologists, specialist nurses and patient support group representatives. The GDG Committee agreed the remit of the guidelines and selected a list of guidelines topics for development.

A systematic literature review on NPC in the last 10 years until May 2017 was carried out using Medline, MedLink, Embase and the Cochrane Library. Relevant papers, which were previously published were considered by the GDG members as important were included. Searches were limited to English language publications only. The initial search identified 879 reference abstracts, of which 276 were accepted as relevant after the first screen. References related to a single topic (i.e., Epidemiology, Genetics, Pathophysiology, Clinical Diagnosis, Laboratory, Imaging, Therapy, Recommendations) were pulled together and the GDG was divided into subgroups aimed to critically appraise references devoted to a specific topic. The committee met twice (June 2016, Birmingham, UK and September 2016, Rome, Italy) and corresponded by email on a regular basis throughout the duration of the guideline development. During the first workshop, the GDG adopted the second version of the Appraisal of Guidelines for Research \& Evaluation (AGREE II) system as methodological reference in order to meet the guideline development standards outlined in the AGREE II system: howewer, our guideline didn't partially or completely met $5 / 23$ items outlined in the AGREE II system, and we haven't calculated quality scores for all appraisal items [1].

Relevant papers were evaluated by members of the GDG before the evidence was considered. Section leaders individually assessed the literature selected and wrote a short document describing the study findings and related recommendations. All GDG members discussed the draft documents. Evidence levels were classified in accordance with the Grading of Recommendations, Assessment, Development and Evaluations (GRADE) methodology and recommendations were graded from A to $C$ (Table 1). In addition, for the adoption of recommendations, we structured a panel of experts that represented group of specialists caring for NPC patients and used the Delphi method for the development of our guidelines. In total, 25 persons participated, and after the first round of Delphi consensus two statements required substantial revision and the expert opinion expressed in the guidelines were based on the revised statements.

The guidelines will be published in an open access journal and made freely accessible through the INPDR and INPDA website. These guidelines will be revised every 3-5 years to reflect new data pertaining to future research findings, new therapies and the development of diagnostic methods. The development of these guidelines was made without external financial support from industries involved in the manufacturing of therapies for NPC disease. Competing interests of members of the guideline development group have been recorded in writing and addressed. Developing treatment guidelines in an objective and scientific manner for a rare disease is challenging owing to the lack of randomized controlled trials (RCT). We have attempted to apply all the AGREE II domains in our guidelines development. However, as the methodology was developed for common disorders, where there is wealth of evidence in a 
Table 1 Evidence levels and strength of recommendations

\begin{tabular}{|c|c|}
\hline Item & Definition \\
\hline \multicolumn{2}{|l|}{ Level of evidence } \\
\hline A. High-quality evidence & $\begin{array}{l}\text { Further research is unlikely to } \\
\text { change our confidence in the } \\
\text { estimate of effect. Consistent } \\
\text { evidence from the RCTs without } \\
\text { important limitations or } \\
\text { exceptionally strong evidence } \\
\text { from observational studies. }\end{array}$ \\
\hline B. Moderate-quality evidence & $\begin{array}{l}\text { Further research is likely to have } \\
\text { an important impact on our } \\
\text { confidence in the estimate of } \\
\text { effect and may change the } \\
\text { estimate. Evidence from RCTs } \\
\text { with important limitations } \\
\text { (inconsistent results, } \\
\text { methodologic flaws, indirect or } \\
\text { imprecise), or very strong } \\
\text { evidence from observational } \\
\text { studies. }\end{array}$ \\
\hline C. Low-quality evidence & $\begin{array}{l}\text { Further research is very likely to } \\
\text { have an important impact on our } \\
\text { confidence in the estimate of } \\
\text { effect and is likely to change the } \\
\text { estimate. Evidence for at least } \\
\text { one critical outcome from } \\
\text { observational studies, case series, } \\
\text { or from RCTs with serious flaws, } \\
\text { or indirect evidence, or expert's } \\
\text { consensus. }\end{array}$ \\
\hline \multicolumn{2}{|l|}{ Strength of recommendation } \\
\hline 1. Strong recommendation & $\begin{array}{l}\text { Recommendation can apply to } \\
\text { most patients in most } \\
\text { circumstances. }\end{array}$ \\
\hline 2. Weak recommendation & $\begin{array}{l}\text { The best course of action may } \\
\text { differ depending on } \\
\text { circumstances or patient or } \\
\text { society values. Other alternatives } \\
\text { may be equally reasonable. }\end{array}$ \\
\hline
\end{tabular}

form of RCT, a large number of patients cared by large number of clinical units, despite our best effort, we found it difficult to apply AGREE II in full for an ultrarare disorder. The small number of patients available for clinical studies, variability of the phenotype and constraints on funding limit the opportunities to mount clinical trials. We have therefore created guidelines using the best available data, however imperfect it may be.

\section{Defintion and epidemiology Definition of NPC}

Statement \#1: NPC is a progressive and life limiting autosomal recessive disorder caused by mutations in either the NPC1 or NPC2 gene. Mutations in these genes are associated with abnormal endosomal-lysosomal trafficking, resulting in the accumulation of multiple lipids in the lysosomes. Disease onset occurs through the lifespan, from antenatal life to maturity.
- Strength of recommendation: 1

- Level of evidence: $B$

- Experts opinion: completely agree (94\%), mostly agree (6\%), partially agree (0\%), mostly disagree (0\%) and completely disagree (0\%).

Niemann-Pick disease type C (OMIM\#257220; OMIM \#607625) is a lysosomal storage disorder caused by mutations in either NPC1 or NPC2 genes [2-4]. The two genes code for their respective proteins, NPC1 and NPC2 $[5,6]$. The two proteins, working in a coordinated manner, are believed to be involved in the cellular trafficking of cholesterol [7] and other lipids in the late endosomal/post-lysosomal stage of lipid transport. Disease causing mutations in either gene result in tissue accumulation of multiple lipids (see Ref [8] for review). Both types of NPC are inherited in an autosomal recessive manner. NPC disease is a progressive disorder characterized by neuro-visceral manifestations that can present at any age from the perinatal period to maturity. Life expectancy in patients with NPC disease varies with the age of onset of the disease and ranges from a few days to several decades [9-13].

\section{How common is NPC disease?}

Statement \#2: NPC disease is rare, with an estimated incidence of 1 case per 100,000 live births. The disease is pan-ethnic, with at least $95 \%$ of all disease due to mutations in the NPC1 gene and the remainder in the NPC2 gene.

- Strength of recommendation: 2

- Level of evidence: $C$

- Experts opinion: completely agree (65\%), mostly agree (29\%), partially agree (6\%), mostly disagree (0\%) and completely disagree (0\%).

Retrospective national expert centre based studies from Australia, the Netherlands, the UK, Portugal, Czech Republic, France and United Arab Emirates have reported an annual incidence varying between 0.25 and 2.20 per 100,000 live births $[11,14-18]$. Published incidence data that includes information from prior to 1990 may underestimate the disease prevalence. These figures should be compared with those recently compiled from parallel large exome sequencing datasets [19]. In the latter study, when taking into account pathogenic mutations, the incidence rate at conception of classical clinical forms of NP-C was calculated to 1.12 per $100,000(1 / 89,229)$. In addition, owing to better awareness and improved diagnostic methods, a significantly higher proportion of adult-onset cases have been diagnosed during the past 5 years [20], therefore a recalculation would likely approach a figure slightly higher than 
$1 / 100,000$. Interestingly, in the Wassif et al. study, the inclusion of two variants of controversial pathogenicity would suggest a much higher incidence in the range of $1 / 40,000$ of still unrecognized late onset, milder form [19]. Indeed, attenuated phenotypes may not be suspected clinically, or may be missed by the diagnostic laboratories.

\section{Clinical presentation}

\section{How best can NPC disease be classified?}

Statement \#3: The clinical manifestations and life expectancy of NPC patients vary markedly with age of onset of the disease. In neonates and children, NPC may initially present as a systemic disease with subtle neurological manifestations, but for practical purposes, NPC is best classified according to the age of onset of neurological manifestations as follow:

1. visceral-neurodegenerative form

- Early-infantile (<2 years)

2. neurodegenerative form

- Late-infantile (2-6 years)

- Juvenile (6-15 years)

3. Psychiatric-neurodegenerative form

- Adult (>15 years)

- Strength of recommendation: 1

- Level of evidence: $B$

- Experts opinion: completely agree (50\%), mostly agree (38\%), partially agree (13\%), mostly disagree (0\%) and completely disagree (0\%).

The clinical spectrum of NPC disease ranges from a neonatal rapidly progressive fatal disorder to an adultonset chronic neurodegenerative disease. Based on data gathered from a large cohort of French NPC patients, the age of onset of neurological symptoms predicts the severity of the disease and determines life expectancy [11]. Disease classifications based on the age of onset of the first (beyond 3 months of life) neurological symptom may be used to guide clinicians in providing day to day care, genetic counselling and estimate the trajectory of the disease course. There is an overlap between the neurological forms, as NPC disease comprises a continuum [20]. Relative distributions of the five age categories based on the national/international registry are listed in Table 2. In addition, atypical presentations such as: a) the fatal systemic perinatal form (foetal hydrops or early liver, multi-organ or respiratory failure) and b) initial systemic disease only (in infants and children with a variable latency before onset of neurological manifestations) constitutes a small, but significant, proportion of cases. The global contribution of these forms has rarely been calculated, and such patients are typically not enrolled in registries. Two features emerge from the compiled data presented in Table 2: the early infantile neurological onset form appears more frequent in Southern Europe, and 2) patients with an adolescent/adult onset neurological form seem to represent at least $20 \%$ of the cases of NPC and, owing to their longer survival, probably constitute the largest patient group in terms of disease prevalence [20].

\section{Is the clinical presentation different in specific age groups? \\ Pre/perinatal (<2 months)}

Statement \# 4: NPC manifests in the pre/perinatal age group primarily as liver disease presenting with prolonged cholestatic jaundice, hepatosplenomegaly and in some cases acute liver failure, with or without pulmonary disease.

Table 2 Distribution of clinical forms of NP-C disease in large cohorts

\begin{tabular}{|c|c|c|c|c|c|c|}
\hline & $\begin{array}{l}\text { Neonatal systemic } \\
\text { fatal }(\%)\end{array}$ & $\begin{array}{l}\text { Early infantile } \\
\text { neurological } \\
\text { onset (\%) }\end{array}$ & $\begin{array}{l}\text { Late infantile } \\
\text { neurological } \\
\text { onset (\%) }\end{array}$ & $\begin{array}{l}\text { Juvenile } \\
\text { neurological } \\
\text { onset (\%) }\end{array}$ & $\begin{array}{l}\text { Adolescent/adult } \\
\text { neurological } \\
\text { onset (\%) }\end{array}$ & Total no. \\
\hline \multicolumn{7}{|l|}{ Early studies } \\
\hline France+ European countries [70] & 12 & 30 & 23 & 30 & 5 & 125 \\
\hline Spain [71-73] & 7 & 37 & 21 & 25 & 11 & 57 \\
\hline Italy $[74,75]$ & 7 & 26 & 32 & 23 & 12 & 43 \\
\hline France [11] & 9 & 26 & 22 & 26 & 16 & 107 \\
\hline \multicolumn{7}{|l|}{ Recent studies } \\
\hline Germany [22] & 3 & 3 & 35 & 54 & 5 & 37 \\
\hline Czech Republic [12] & 6 & 17 & 24 & 37 & 17 & 54 \\
\hline UK [13] & 5 & 6 & 39 & 32 & 19 & 132 \\
\hline European countries [20] & - & 11 & 31 & 31 & 27 & 145 \\
\hline
\end{tabular}


- Strength of recommendation: 1

- Level of evidence: $B$

- Experts opinion: completely agree (60\%), mostly agree (40\%), partially agree (0\%), mostly disagree (0\%) and completely disagree (0\%).

NPC disease presentation during the neonatal period varies from subject to subject, with the commonest presentation being prolonged jaundice and mild hepatosplenomegaly. In the majority of cases, jaundice resolves spontaneously by 3-4 months of age, while organomegaly persists to a variable degree. Neurological symptoms develop later, with a delay varying between a couple of months and the childhood period, or even later in a few cases. However, in about $8-9 \%$ of the cases, the hepatic manifestations may progress rapidly to acute liver and/or multi-organ failure and subsequently lead to death within 6 months. In some circumstances, the initial presentation may be foetal ascites/hydrops. The rapidly progressing cohort may have associated neurological presentations such as failure to thrive and hypotonia [10].

Early infantile (2 months to < 2 years):

Statement \#5: Hypotonia and delay in developmental motor milestones characterize the neurological manifestation of NPC in early infancy. Hepatosplenomegaly and/ or a neonatal prolonged jaundice are almost invariably noted.

- Strength of recommendation: 1

- Level of evidence: $B$

- Experts opinion: completely agree (53\%), mostly agree (40\%), partially agree (7\%), mostly disagree (0\%) and completely disagree (0\%).

Hypotonia may be due to cerebral and/or peripheral nerve pathology in these early infantile forms. In the latter case, distal motor limb deficit may be clinically obvious. Communication is initially well preserved. Vertical supranuclear gaze palsy (VSGP) may be present, but is difficult to recognize.

\section{Late infantile ( 2 to $<6$ years)}

Statement \#6: Clumsiness, gait disturbance and fine motor skill impairments characterize this age of onset of the disease. Speech delay, a history of neonatal cholestasis and variable visceromegaly may be noted. VSGP is typically present, but is often unrecognized. The first symptoms may be gelastic cataplexy (sometimes associated with narcolepsy) or sensory deafness. Epilepsy is quite frequent in subsequent evolution in this group.

- Strength of recommendation: 1

- Level of evidence: $B$
- Experts opinion: completely agree (67\%), mostly agree (33\%), partially agree (0\%), mostly disagree (0\%) and completely disagree (0\%).

Juvenile (6 to 15 years)

Statement \#7: Juvenile-onset is the 2nd most frequent presentation of NPC and manifests as cognitive impairment (lagging behind peers in school, language and learning difficulties), coordination problems (clumsiness, frequent falls, progressive ataxia and dystonia) and VSGP.

- Strength of recommendation: 1

- Level of evidence: $B$

- Experts opinion: completely agree (60\%), mostly agree (40\%), partially agree (0\%), mostly disagree (0\%) and completely disagree (0\%).

\section{Adult (> 15 years)}

Statement \#8: Adolescent and adult-onset NPC patients may represent up to a third of all NPC patients. Cognitive impairment invariably occurs and tends to present with higher rates of psychiatric illness co-existing with neurological manifestations. Diagnostic delay is common, but is minimised if the characteristic VSGP is identified.

- Strength of recommendation: 1

- Level of evidence: $B$

- Experts opinion: completely agree (27\%), mostly agree (67\%), partially agree (7\%), mostly disagree (0\%) and completely disagree (0\%).

The age of onset of NPC varies significantly across the lifespan (Table 3) [11], although increasingly patients are recognized as presenting with late-onset illness in adolescence, early and mid-adulthood and may present as late as the 7th decade [21]. Early development is often completely normal achieving all developmental milestones appropriate to their age. In a large international prospective registry, the adolescent and adult-onset form occurred in $27 \%$ of all NPC patients [20]. Patients in this age group are less likely to present with seizures, gelastic cataplexy and diagnosed visceral disease. Typical presentation is a history of progressive ataxia/dystonia, and/or cognitive decline, and/or atypical psychotic symptoms, often associated to vertical gaze palsy at clinical examination [11, 22-25]. Other reported symptoms dysarthria and dysphagia are also very frequent but occur later. Some patients may have previous symptoms that have begun several years before onset of the chronic neurodegenerative disease such as undiagnosed hepatomegaly or splenomegaly with spontaneous remission in childhood, learning disorder in childhood, and hearing defect. In late-onset patients, diagnostic delay is common and is 
Table 3 Summary of Clinical signs and symptoms in NP-C, by age of onset

\begin{tabular}{|c|c|c|}
\hline Age at onset & Systemic manifestations & Neurological/psychiatric manifestations \\
\hline \multirow[t]{7}{*}{ Pre-/peri-natal (< 2 months) } & Foetal ascites/hydrops & \multirow[t]{7}{*}{ Hypotonia } \\
\hline & Hepatosplenomegaly & \\
\hline & Cholestatic jaundice & \\
\hline & Thrombocytopenia & \\
\hline & Pulmonary disease & \\
\hline & Liver failure & \\
\hline & Failure to thrive & \\
\hline \multirow[t]{3}{*}{ Early-infantile ( $2 \mathrm{~m}$ to $<2 \mathrm{yrs}$.) } & $\begin{array}{l}\text { Hepatosplenomegaly or Splenomegaly } \\
\text { (isolated or with neurological manifestations) }\end{array}$ & $\begin{array}{l}\text { Central hypotonia } \\
\text { Delayed developmental motor milestones, } \\
\text { speech delay }\end{array}$ \\
\hline & \multirow[t]{2}{*}{ Prolonged neonatal jaundice } & Dysphagia, spasticity \\
\hline & & VSGP \\
\hline \multirow[t]{7}{*}{ Late-infantile ( 2 to $<6$ yrs.) } & $\begin{array}{l}\text { Hepatosplenomegaly or Splenomegaly } \\
\text { (isolated or with neurological manifestations) }\end{array}$ & Developmental delay/regression, speech delay \\
\hline & \multirow{6}{*}{$\begin{array}{l}\text { History of prolonged neonatal } \\
\text { cholestatic jaundice }\end{array}$} & Clumsiness, Frequent falls, \\
\hline & & $\begin{array}{l}\text { Progressive ataxia, dystonia, dysarthria, } \\
\text { dysphagia, }\end{array}$ \\
\hline & & Seizures (partial/generalized) \\
\hline & & Cataplexy \\
\hline & & VSGP \\
\hline & & Hearing loss \\
\hline \multirow[t]{6}{*}{ Juvenile (6 to 15 yrs.) } & \multirow[t]{6}{*}{$\begin{array}{l}\text { Hepatosplenomegaly or Splenomegaly (isolated or } \\
\text { with neurological manifestations; often not present) }\end{array}$} & $\begin{array}{l}\text { Poor school performance, learning disability. } \\
\text { Loss of language skill }\end{array}$ \\
\hline & & Frequent falls, clumsiness \\
\hline & & $\begin{array}{l}\text { Progressive ataxia, dysarthria, dystonia, } \\
\text { dysmetria, dyskinesia, dysphagia }\end{array}$ \\
\hline & & VSGP \\
\hline & & $\begin{array}{l}\text { Gelastic cataplexy } \\
\text { Seizures }\end{array}$ \\
\hline & & Behavioural problems \\
\hline \multirow[t]{2}{*}{ Adolescent/adult (> 15 yrs.) } & \multirow[t]{2}{*}{$\begin{array}{l}\text { Splenomegaly (often not present; isolated in } \\
\text { very rare cases) }\end{array}$} & $\begin{array}{l}\text { Cognitive decline, dementia, learning } \\
\text { disability } \\
\text { Psychiatric signs: Schizophrenia (psychosis), } \\
\text { depression. }\end{array}$ \\
\hline & & $\begin{array}{l}\text { Clumsiness, progressive motor symptoms, } \\
\text { tremor, ataxia, dystonia/dyskinesia, dysarthria, } \\
\text { dysphagia } \\
\text { VSGP }\end{array}$ \\
\hline
\end{tabular}

often 5 years or more, although this delay may be minimised when the more specific symptom of VSGP is recognised [26]. Despite the diagnostic utility of VSGP, it may not be present if patients are examined early in the course of the disease, and its absence should not rule out the diagnosis of NPC.

Pre-senile cognitive impairment, prominently affecting memory and executive function, invariably occurs in adolescent and adult-onset NPC patients [23, 26-28]. Furthermore, up to one third of adolescent and adult patients may present with psychiatric symptoms such as psychosis (paranoid delusions, auditory and/or visual hallucination) and depression which predate neurological manifestations and exhibit atypical features, including treatment- resistance $[12,26,29,30]$. Up to one third of patients presenting with psychiatric illness, most commonly psychosis, may show a poor response to treatment. The combination of psychiatric and neurological presentation should raise the clinical suspicion of a diagnosis of NPC.

The NPC-suspicion index assists in the diagnosis of adult patients with NPC, with strong indicators including cognitive and psychotic symptoms, and the combination of neurological with psychiatric signs is 
highly suggestive of NPC [26, 31]. NPC patients may have initially a poorly specific presentation, but with accumulation of typical disorders, probability of diagnosis strongly increases, as illustrated by the series of ataxia clinic patients with recessive disease and cognitive decline for whom NPC was genetically confirmed in one sixth of them [25].

\section{Conditions raising the suspicion of NPC and differential diagnosis}

The symptoms and signs of NPC vary with age at disease onset. There are numerous conditions raising the suspicion of NPC and other age appropriate diseases should also be excluded.

Statement \#9: In the first 2 years of life, history of prolonged neonatal jaundice, hepatosplenomegaly and/or developmental delay should raise the possibility of NPC. The differential diagnosis includes other causes of cholestatic jaundice, idiopathic neonatal hepatitis, Wolman disease, Niemann-Pick type A/B, Gaucher type III disease and Cerebrotendinous xanthomatosis with or without initial developmental delay.

- Strength of recommendation: 1

- Level of evidence: $B$

- Experts opinion: completely agree (50\%), mostly agree (36\%), partially agree (14\%), mostly disagree (0\%) and completely disagree (0\%).

Statement \#10: From childhood to adolescence, neurological disease manifestations can be subtle, ranging from clumsiness and poor school performance to progressive ataxia, dysarthria and dystonia. Other age appropriate neurodegenerative disorders must be ruled out.

- Strength of recommendation: 1

- Level of evidence: $B$

- Experts opinion: completely agree (73\%), mostly agree (27\%), partially agree (0\%), mostly disagree (0\%) and completely disagree (0\%)

NPC can also manifest as isolated splenomegaly or hepatosplenomegaly and mimics NPB disease (same storage cells) or Gaucher disease. NPC should be considered in differential diagnosis in patients with unexplained isolated splenomegaly with or without hepatomegaly at any age.

Statement \#11: Adult patients presenting with an atypical psychotic disorder or a progressive neurological syndrome including ataxia, dystonia, cognitive difficulties, dysarthria, or VSGP with or without splenomegaly should be tested for NPC. Other neurodegenerative disorders such as Huntington disease, Wilson disease, Cerebrotendinous xanthomatosis, GM1 or GM2 gangliosidoses and Friedreich Ataxia which mimic NPC must be ruled out. However, on the contrary to several of those diseases, in NPC patients, there is no peripheral neuropathy and brain MRI is normal or shows nonspecific abnormalities (mainly atrophy).

- Strength of recommendation: 1

- Level of evidence: $B$

- Experts opinion: completely agree (67\%), mostly agree (33\%), partially agree (0\%), mostly disagree (0\%) and completely disagree (0\%).

\section{NPC disease severity score}

Statements \#12: NPC-specific disease severity scores are useful adjuncts to clinical judgement in assessing disease burden, response to therapy and determining prognosis.

- Strength of recommendation: 1

- Level of evidence: $B$

- Experts opinion: completely agree (53\%), mostly agree (40\%), partially agree (7\%), mostly disagree (0\%) and completely disagree (0\%).

Clinical assessment of disease severity is dependent on the experience of the treating clinician, but such clinical judgement may not be reliable when the disease is rare and most clinicians have limited exposure to the condition. Three severity scoring systems and predictive models have been developed in an attempt to help the clinician accurately assess disease burden and monitor progression in time or stabilisation with therapy and estimate prognosis at an early stage [22, 24, 32]. These NPC-specific scales were based on neurological impairments that allow a calculation of a composite score to assess disease severity. Bearing in mind the resources available to most physicians in practice, we suggest the use of a modified version (Table 4) of the widely implemented and user-friendly model [24] though it has not been formally validated for treatment monitoring. No predictive model allows the unequivocal categorisation of patients into definite groups and predictive models are best viewed as useful adjuncts to clinical judgement. Regular reassessment of severity over the course of the disease is mandatory to assess the response to treatment.

\section{Is saccadic eye movement evaluation a measure of disease status?}

Statements \#13: Measures of horizontal saccadic function are robust objective measures of illness status and correlate with indices of brain structure.

- Strength of recommendation: 2

- Level of evidence: B 
Table 4 Clinical Severity assessment

\begin{tabular}{|c|c|}
\hline \multicolumn{2}{|c|}{ I. Functional disability scale (Modified from Pineda et al. [24]) } \\
\hline Ambulation & Score \\
\hline Normal & 0 \\
\hline Clumsiness & 1 \\
\hline Autonomous ataxic gait & 2 \\
\hline Outdoor assisted ambulation & 3 \\
\hline Indoor assisted ambulation & 4 \\
\hline Wheelchair-bound & 5 \\
\hline Manipulation & Score \\
\hline Normal & 0 \\
\hline Tremor & 1 \\
\hline $\begin{array}{l}\text { Slight dysmetria/dystonia (allows autonomous } \\
\text { manipulation) }\end{array}$ & 2 \\
\hline $\begin{array}{l}\text { Mild dysmetria/dystonia (requires help for } \\
\text { several tasks but is able to feed themselves) }\end{array}$ & 3 \\
\hline $\begin{array}{l}\text { Severe dysmetria/dystonia (requires assistance } \\
\text { in all activities) }\end{array}$ & 4 \\
\hline Language & Score \\
\hline Normal & 0 \\
\hline Delayed acquisition & 1 \\
\hline Mild dysarthria (understandable) & 2 \\
\hline $\begin{array}{l}\text { Severe dysarthria (only comprehensible to } \\
\text { some family members) }\end{array}$ & 3 \\
\hline Non-verbal communication & 4 \\
\hline Absence of communication & 5 \\
\hline Swallowing & Score \\
\hline Normal & 0 \\
\hline Occasional dysphagia & 1 \\
\hline Daily dysphagia & 2 \\
\hline Nasogastric tube or gastric button feeding & 3 \\
\hline Eye movements & Score \\
\hline Normal & 0 \\
\hline Slow ocular pursuit & 1 \\
\hline Vertical ophthalmoplegia & 2 \\
\hline Complete ophthalmoplegia & 3 \\
\hline Seizure & Score \\
\hline No & 0 \\
\hline Yes, controlled by antiepileptic drugs & 2 \\
\hline $\begin{array}{l}\text { Yes, uncontrolled on two or more } \\
\text { antiepileptic drugs of maximally tolerable dose }\end{array}$ & 4 \\
\hline II. Neurocognitive Assessment & \\
\hline Development (<12 years old): & \\
\hline O Normal & \\
\hline O Mild learning delay & \\
\hline O Moderate learning delay & \\
\hline O Severe delay/plateau & \\
\hline O Regression & \\
\hline
\end{tabular}

Table 4 Clinical Severity assessment (Continued)

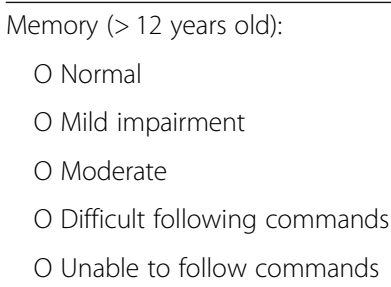

- Experts opinion: completely agree (23\%), mostly agree (23\%), partially agree (46\%), mostly disagree (8\%) and completely disagree $(0 \%)$.

Vertical saccadic gaze palsy is a clinical hallmark of the disease, whereas horizontal saccadic gaze deteriorates less rapidly and is a useful objective biomarker of disease severity illness. Horizontal saccadic gain, which correlates strongly with measures of pontine area and parietal eye field volume as measured on MRI, and selfpaced saccades, an index of frontal eye field integrity, may be the most robust measure in adults [33, 34].

\section{Investigations}

Once NPC is suspected clinically, diagnosis can be confirmed by the combination of biochemical and molecular genetic studies [35]. In recent years, several plasma metabolites (cholestane-3 $\beta, 5 \alpha, 6 \beta$-triol, lyso-sphingomyelin isoforms and bile acid metabolites) have emerged as sensitive and specific diagnostic biomarkers for NPC and their study, completed by genetic analyses, should now be considered as the first line laboratory testing $[35,36]$. The filipin test, although still very useful, is no longer considered as the primary tool. Figure 1 describes a revised laboratory diagnostic algorithm for NPC.

What investigations should be performed in individual suspected with NPC?

\section{Biomarkers}

Statements \#14: Assessment of biomarkers should be considered as a first-line test to screen for NPC. Three classes of biochemical markers are either currently in use (oxysterols; lyso-SM-509 and lyso-sphingomyelin) or are in development (bile acid derivatives). They can be used alone or in combination to enhance sensitivity and specificity. The diagnosis, however, must in all cases be confirmed by mutation analysis and if necessary, filipin test.

- Strength of recommendation: 1

- Level of evidence: $B$

- Experts opinion: completely agree (75\%), mostly agree (13\%), partially agree (13\%), mostly disagree (0\%) and completely disagree (0\%). 


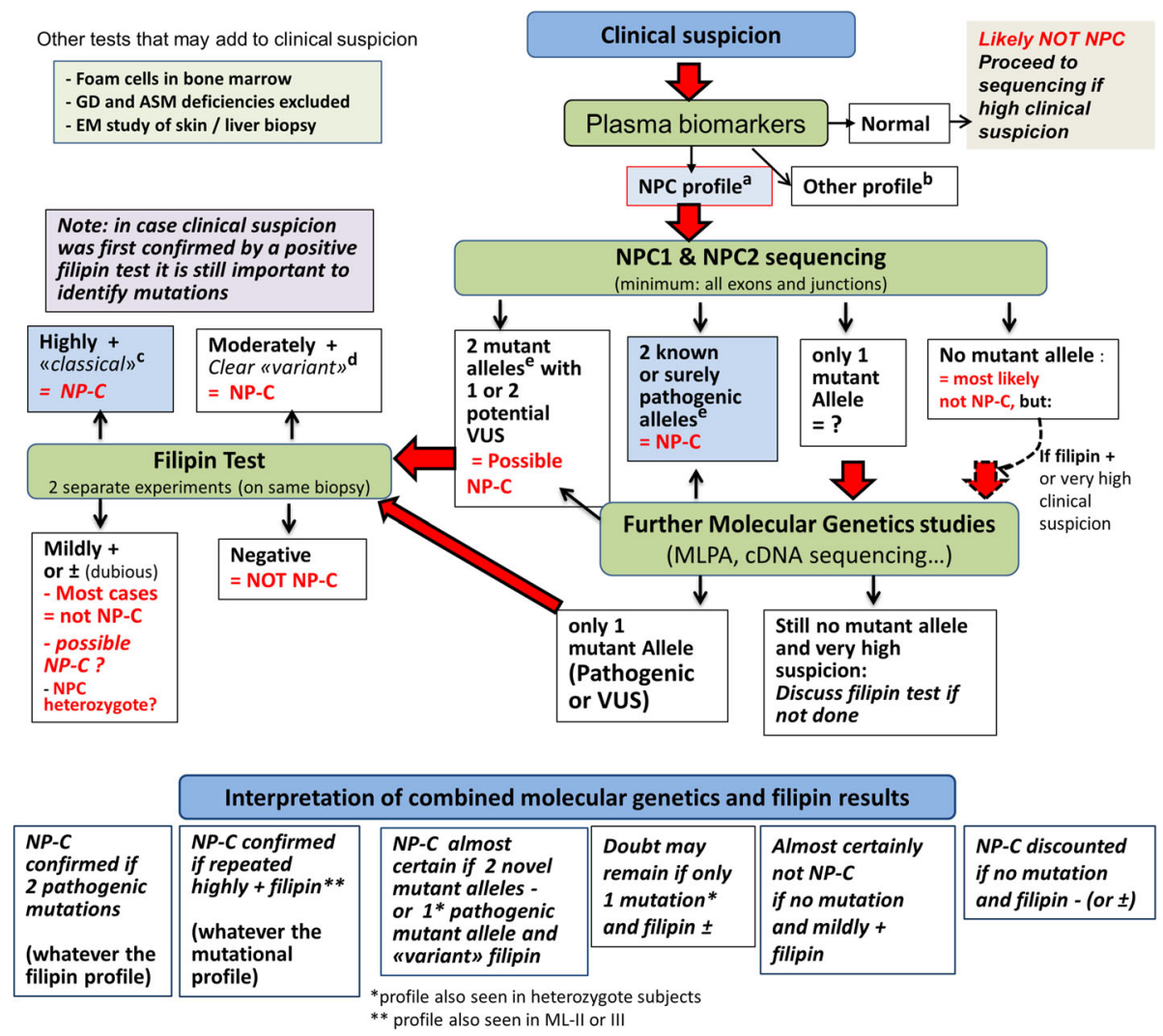

Fig. 1 Niemann-Pick disease type C laboratory diagnosis algorithm. Modified from: Patterson et al. [36, 47]. Abbreviations: GD: Gaucher disease; ASMD: acid sphingomyelinase deficiency; EM: electron microscopy; VUS: variant of unknown significance; MLPA: Multiplex Ligation-dependent Probe Amplification (evaluates copy number changes, allows detection of large deletions or false homozygous status with a deletion on the other allele); lysoSM: Iysosphingomyelin. ${ }^{2}$ Elevated cholestane-triol or bile acid derivative and/or lysoSM-509, with normal or slightly elevated IysoSM. ${ }^{\mathrm{b}}$ Cholestane-triol also elevated in ASMD, acid lipase deficiency, cerebrotendinous xanthomatosis, certain neonatal cholestasis conditions. All IysoSM analogues and bile acid derivative are elevated in ASMD. ฯ -cell disease (ML-II and -III) gives a false positive result (very different clinical features). ${ }^{d}$ ASMD can give a similar filipin pattern. ${ }^{e}$ Check allele segregation by parental study or other test

\section{Oxysterols (cholesterol oxidation products)}

The oxysterols cholestane- $3 \beta, 5 \alpha, 6 \beta$-triol (C-triol) and 7-ketocholesterol (7-KC), are well established and accessible to clinicians (implemented in $>30$ clinical laboratories worldwide). Both are sensitive markers of NPC, though C-triol is more specific [37, 38].

Potential limitations:

- Elevated values have been reported in other metabolic disorders, particularly acid sphingomyelinase deficiency and lysosomal acid lipase deficiency, and to a lesser degree Cerebrotendinous xanthomatosis and Smith Lemli Opitz syndrome. These false positive results may reflect artefacts of the derivatization process used in the assay.

- Spurious values in the setting of neonatal cholestasis may result from assay interference. In this clinical setting, plasma bile acids are test of choice (see below).
- Overlap between upper quartile of NPC1 carriers and NPC1 patients must be considered when screening populations with low carrier frequency (e.g., general population).

\section{Lyso-sphingolipids}

The simultaneous mass spectrometric measurement in plasma of lyso-sphingomyelin (lyso-SM) (also known as sphingosyl-phosphorylcholine) [39] and of an analogue of unclear structure named lyso-sphingomyelin 509 (lyso-SM 509) appears as a very promising tool for initial screening of patients with either NPC or acid sphingomyelinase deficiency (ASMD) [39-44]. Striking elevations of Lyso-SM 509 have been reported in both NPC and ASMD, with high sensitivity for detecting both disorders, but poor distinction between them. For lyso-SM, a large increase only occurs in ASMD, with marginal or no elevation in NPC. Therefore, the combined assay of lyso-SM 509 and lyso-SM provides a good discrimination between 
NPC and ASMD. A high lysoSM-509/lysoSM ratio appears very specific of NPC. Further simultaneous measurement of other lysosphingolipids (e.g. glucosylsphingosine) in the same analysis can also discriminate other sphingolipidoses of clinical relevance - particularly Gaucher disease [42, 44].

Potential limitations:

- The structure of lyso-SM-509 is unknown, and exact concentrations cannot be measured

- Experience of clinical laboratories with Lyso-SM-509 and lyso-SM is still limited.

- Specificity of lyso-SM-509 among sphingolipidoses other than NPC and ASMD appears good [42-44] but will require further studies.

- It is still unclear whether this biomarker can discriminate between NPC1 carriers and NPC1 patients, which has implications for population screening.

\section{Bile acids}

Several unusual bile acid species in plasma and urine have been identified in NPC. The most important analytical species is $3 \beta, 5 \alpha, 6 \beta$-trihydroxy-cholanoylglycine, detectable in plasma and dried blood spots $[45,46]$.

Potential benefits:

- It is highly sensitive and more specific than oxysterols (only elevated in acid sphingomyelinase deficiency and NPC).

- From available data, it provides complete discrimination between NPC1 carriers and NPC1 patients, suggesting it may be a biomarker of choice for population screening.

- It does not require derivatization and is less prone to interferences in the context of neonatal cholestasis, suggesting it may be the test of choice for diagnosing NPC disease in this clinical subset.

- This biomarker has greater stability than C-triol and can be shipped to diagnostic laboratories at ambient temperature.

Potential limitations:

- Test is new and performed at present in only a couple of research institutions.

- The biomarker has not been validated prospectively in clinical laboratories.

Good correlation has been observed between levels of the 3 biomarkers cholestane-triol, trihydroxycholanoylglycine and lyso-SM-509 in the same patient, but, from limited data, not necessarily with the level of lysosomal cholesterol storage observed in the filipin test.

\section{Molecular genetic studies:}

Statements \#15: Any individual in whom the diagnosis of NPC is considered based on their clinical manifestation and/or abnormal biomarker profile should undergo genetic testing for NPC genes to confirm the diagnosis. Referral to a clinical geneticist or genetic counsellor should be considered upon the diagnosis of NPC.

- Strength of recommendation: 1

- Level of evidence: $A$

- Experts opinion: completely agree (81\%), mostly agree (19\%), partially agree (0\%), mostly disagree (0\%) and completely disagree (0\%).

Mutation analysis of NPC1 and NPC2 genes is mandatory to confirm the diagnosis of NPC. In addition, it is the only reliable method to diagnose NPC carriers within the family and the highly preferred strategy for prenatal diagnosis. Furthermore, it may be useful to establish genotype-phenotype correlations. However, some genetic changes (e.g. deep intronic mutations, large deletions/ duplications) may not be identified by routine sequencing methods and will require complementary testing [47]. Nonetheless, a small proportion of mutated NPC1 alleles have remained unidentified in proven patients. The segregation of the alleles should be confirmed in parents. The identification of two alleles with known disease-causing mutations in either NPC1 or NPC2 gene confirms the diagnosis of NPC. To date, about 700 NPC1variants have been reported, among which around 420 are considered as pathogenic, with only a limited number of common (p.I1061T, p.P1007A) or recurrent (often in certain populations) mutations. Thus, the interpretation of new missense and splicing mutations should be undertaken with caution and their pathogenic nature must be verified.

Although genotype/phenotype correlations are difficult to establish, some conclusions can be drawn from current evidence:

The presence in both alleles of a very severe mutation (frameshift, nonsense, large deletion) usually results in early-infantile neurological disease (with also a higher risk of severe - possibly fatal - neonatal systemic disease). From observations in homozygous patients, an increasing number of recurrent NPC1 missense mutations (e.g. p.G1240R) can also be classified in this category.

The p.I1061T NPC1 mutation $[48,49]$ has been reported in a large number of individuals; in homozygosity, it has mostly been associated with a juvenile 
neurological onset, less frequently with a late infantile neurological phenotype. In heterozygosity, depending on the second mutation, it is also often found in patients with an adolescent/adult onset form [13].

The p.P1007A NPC1 mutation appears more commonly associated with a juvenile or adult onset form than with a late infantile one [22, 50]. Patients carrying this mutation (even on one allele) have been difficult to diagnose using the filipin test, as p.P1007A is the prototype of NPC1 mutations associated with a less severe block in cholesterol egress from lysosomes, resulting in the so-called "variant" filipin phenotype [50].

Lately, an increasing number of recurrent NPC1 missense mutations associated with a late-onset neurological form (e.g. p.R978C, p.G992R, p.D874V), have been reported even when found in compound heterozygosity with a severe or null allele.

Thus far, 26 pathogenic NPC2 mutations have been described. Most are frameshift or nonsense as well as a large deletion variants leading to a severe clinical phenotype. Among the reported missense mutations, two variants (p.V39 M and p.P120S) have been associated with the juvenile or adult forms of the disease. More patients originating from North Africa, Italy and Turkey have been described with NPC2 mutations.

Finally, studies of numerous multiplex families have indicated that mutations (either NPC1 or NPC2) appear largely predictive of the neurological course, and not of the systemic disease.

\section{The Filipin test}

What is the diagnostic role of the filipin test in the era of new biomarkers?

Statements \#16: Filipin test is no longer considered a first line test for the diagnosis of NPC. It still remains an extremely useful diagnostic tool in uncertain cases in which biomarkers and/or molecular analysis present inconclusive results and to assess the pathogenicity of novel genetic variants.

- Strength of recommendation: 1

- Level of evidence: $A$

- Experts opinion: completely agree (81\%), mostly agree (19\%), partially agree (0\%), mostly disagree (0\%) and completely disagree (0\%).

Until recently, the demonstration of unesterified cholesterol accumulation within the lysosomes by filipin testing was considered to be the gold standard test for the diagnosis of NPC disease $[11,47,51]$. Since this assay needs to be performed on cultured fibroblasts obtained from skin biopsies, it is invasive and has a long turnaround time. Additionally, the assay is technically challenging, labour intensive and is performed only in specialized laboratories
[51]. Due to these drawbacks, and in the light of the recent discovery of several sensitive and specific blood biomarkers, filipin staining is no longer considered as a first line test for the diagnosis of NPC [35]. However, it is very useful to assess the pathogenicity of novel genetic variants. It also remains a useful diagnostic tool in uncertain cases in which biomarkers and/or molecular analysis present inconclusive results. In particular, it is important to keep in mind that to date all biomarkers, except bile acids which have not yet been fully validated, do not completely differentiate between heterozygous and affected patients [39, 52, 53]. In these cases, if only one pathogenic mutation is found by molecular analysis of $N P C 1$ and $N P C 2$, filipin testing should be performed. In some cases, distinction between a "variant" filipin profile and the slightly abnormal filipin profile observed in a number of NPC heterozygotes may however be difficult. Consequently, in a few patients, it may not be possible to definitively conclude in spite of comprehensive investigations.

\section{Brain imaging}

What is the role of brain imaging in the diagnosis and follow-up of NPC?

Statements \#17: Brain imaging changes in individuals with NPC are variable and non-specific, but the most commonly reported changes are reductions in volume of the cerebellum, hippocampus, and subcortical grey matter, in addition to subtle changes in most white matter regions.

- Strength of recommendation: 1

- Level of evidence: $B$

- Experts opinion: completely agree (47\%), mostly agree (53\%), partially agree (0\%), mostly disagree (0\%) and completely disagree (0\%).

Neuroimaging data gathered primarily from adolescent and adult individuals with NPC show a variable pattern, with some being normal, particularly early in the course of the illness, while most patients will demonstrate cerebellar volume changes, which correlate with measures of ataxia and ocular-motor function [54]. Reductions in the volume of the hippocampus, basal ganglia and thalamus are also associated with progressive illness [55]. White matter disease is often widespread, most detectable as changes on diffusion imaging [56] or visually as atrophy of the corpus callosum [57]. Increased pontine to mid-brain ratio, much like that seen in progressive supranuclear palsy, is seen, albeit to a lesser degree [58]. In some patients, brain atrophy may predominantly affect frontal and temporal regions [59]. However, these changes are often subtle 
and non-specific, and may be more useful as illness biomarker than as a diagnostic tool.

\section{Managment}

NPC disease is not yet curable but is an eminently treatable condition. Optimal disease management employs a multi-disciplinary, multi-professional team based in a specialist centre, closely liaising with community care providers (Table 5). The mainstay of therapy is symptom management employing disease modifying agent(s) when available.

Statements \#18: Patients with NPC exhibit multisystem disease manifestations and benefit from multidisciplinary follow up from physicians and allied health care professionals with experience in this condition. Wherever possible, patients identified with NPC should be referred to a centre with expertise in the care of this condition.

- Strength of recommendation: 1

- Level of evidence: $A$

- Experts opinion: completely agree (100\%), mostly agree (0\%), partially agree (0\%), mostly disagree (0\%) and completely disagree (0\%).

\section{Symptomatic therapy}

What symptomatic therapy should be considered for a patient with NPC disease?

The following functional assessments should take place at the time of diagnosis or symptom onset and at regular intervals thereafter for optimal symptom control and functional capacity (Table 6).

\section{Growth and developmental delay}

Statements \#19: The growth of children with NPC (height, weight and head circumference) should be assessed at regular intervals as part of routine health assessments by their primary health care provider. In addition, their developmental progress should be monitored using age appropriate instruments.

- Strength of recommendation: 1

- Level of evidence: $B$

- Experts opinion: completely agree (80\%), mostly agree (20\%), partially agree (0\%), mostly disagree (0\%) and completely disagree (0\%).

\section{Mobility}

Statements \#20: Mobility, balance, core stability, trunk control, spasticity, foot posture and strength should be

Table 5 Multidisciplinary assessments of patients with NPC

\begin{tabular}{|c|c|c|}
\hline Discipline & Features of NPC for which this discipline may be of assistance & Reference \\
\hline Primary care physician & $\begin{array}{l}\text { Assist with general medical care; coordinate specialists; } \\
\text { provide support for family }\end{array}$ & Expert opinion \\
\hline Metabolic diseases specialist & $\begin{array}{l}\text { Diagnosis of NPC and exclusion of other disorders in the } \\
\text { differential diagnosis; ongoing patient assessment for } \\
\text { disease progression and response to therapy }\end{array}$ & [47] \\
\hline Neurologist & Cataplexy, movement disorders, dystonia, and seizures & [60] \\
\hline Psychiatrist & Psychosis, behavioural disturbances, depression & [26] \\
\hline Neuro-ophthalmologist & $\begin{array}{l}\text { Diagnosis (vertical gaze palsy) and assess response to therapy } \\
\text { (changes in saccadic eye movement velocity) }\end{array}$ & [61] \\
\hline Anaesthesiologist & Assess for anaesthetic risk as needed & {$[76,77]$} \\
\hline Neuropsychologist & $\begin{array}{l}\text { Assess for cognitive involvement at baseline and in } \\
\text { response to therapy }\end{array}$ & [63] \\
\hline Speech and language therapist & $\begin{array}{l}\text { Assess for dysphagia and aspiration risk; speech } \\
\text { therapy for children }\end{array}$ & Expert opinion \\
\hline $\begin{array}{l}\text { Occupational and physical } \\
\text { therapists/Rehabilitation physician }\end{array}$ & $\begin{array}{l}\text { Assess development and develop aids and home } \\
\text { adjustments as needed for patients with communication } \\
\text { and physical challenges }\end{array}$ & [64] \\
\hline Orthopaedic surgeon & $\begin{array}{l}\text { Assess the need for surgical correction of severe scoliosis, } \\
\text { osteo-articular retractions, spasticity treatments and } \\
\text { hip problems. }\end{array}$ & Expert opinion \\
\hline Nutritionist/Gastroenterologists & $\begin{array}{l}\text { Assess nutritional status in patients who may be losing } \\
\text { weight due to dysphagia or side effects of therapy; } \\
\text { Gastrostomy tube insertion when swallowing is unsafe. }\end{array}$ & [65] \\
\hline Social worker & $\begin{array}{l}\text { Support of patients and families living with disabilities } \\
\text { who require enhanced resources in the community }\end{array}$ & Expert opinion \\
\hline Genetic counsellor & $\begin{array}{l}\text { Provide counselling for families as to recurrence risk } \\
\text { and options for prenatal diagnosis if desired }\end{array}$ & [47] \\
\hline
\end{tabular}


Table 6 Recommended assessments

\begin{tabular}{|c|c|c|c|}
\hline Recommended assessment & Rationale & Frequency & References \\
\hline Baseline history & $\begin{array}{l}\text { Establish current level of disease severity and } \\
\text { retrospectively estimate rate of progression }\end{array}$ & At diagnosis & {$[9,62,78]$} \\
\hline Interval history & $\begin{array}{l}\text { Establish rate of disease progression; monitor for } \\
\text { compliance with and side effects from therapy; } \\
\text { monitor for conditions which would prompt } \\
\text { discontinuation of therapy }\end{array}$ & 6 months & {$[62,78]$} \\
\hline Physical examination & $\begin{array}{l}\text { Document growth parameters, assess for } \\
\text { neurological features and organomegaly }\end{array}$ & At diagnosis then every 6-12 months & {$[61,62]$} \\
\hline NPC clinical severity score & $\begin{array}{l}\text { Document key features of disease at diagnosis, } \\
\text { progression and response to therapy }\end{array}$ & At diagnosis and then every 6 months & {$[22,24,32,61]$} \\
\hline Neuropsychiatric evaluation & $\begin{array}{l}\text { Document and treat psychiatric manifestations } \\
\text { and response to therapy }\end{array}$ & At diagnosis then every 6-12 months & {$[62,79]$} \\
\hline $\begin{array}{l}\text { Developmental or cognitive } \\
\text { assessment }\end{array}$ & $\begin{array}{l}\text { Document baseline degree of cognitive } \\
\text { impairment and monitor response to therapy }\end{array}$ & $\begin{array}{l}\text { At diagnosis; every } 6 \text { months in children; } \\
\text { every } 12 \text { months in adults }\end{array}$ & {$[9,47,61,80]$} \\
\hline Ophthalmology evaluation & $\begin{array}{l}\text { Document saccadic eye movement velocity and } \\
\text { presence of gaze palsy at baseline and document } \\
\text { response to miglustat therapy in treated patients }\end{array}$ & $\begin{array}{l}\text { At diagnosis; at } 6 \text { and } 12 \text { months; after starting } \\
\text { treatment; frequency after } 12 \text { months can be } \\
\text { determined by clinical response }\end{array}$ & {$[61]$} \\
\hline Audiometry & Document presence of hearing loss & At diagnosis then every 12 months & {$[81]$} \\
\hline Swallowing assessment & $\begin{array}{l}\text { Clinical swallowing assessment in all patients; } \\
\text { videofluoroscopic swallowing (VFS) assessment } \\
\text { may be useful in some patients; Document } \\
\text { presence of dysphagia and aspiration and } \\
\text { response to therapy }\end{array}$ & $\begin{array}{l}\text { At diagnosis and then every } 6 \text { months in children; } \\
\text { in adults, frequency could be reduced to every } \\
12 \text { months if asymptomatic and disease is stable }\end{array}$ & {$[61,82]$} \\
\hline Neuroimaging & $\begin{array}{l}\text { Magnetic resonance imaging or more detailed } \\
\text { forms of neuroimaging including MR } \\
\text { spectroscopy and diffusion tensor imaging }\end{array}$ & $\begin{array}{l}\text { At baseline if available; Decisions about follow } \\
\text { up neuroimaging will depend on local availability } \\
\text { and need for general anaesthesia }\end{array}$ & {$[47,83-85]$} \\
\hline
\end{tabular}

assessed regularly by a suitably qualified physical therapist. Strategies to maintain optimal mobility and reduce falls such as providing an appropriate walking/mobility aids, ankle-foot orthotics and exercise programs should be sought proactively. A structured and personalized rehabilitation program may prolong mobility and transfer ability.

- Strength of recommendation: 1

- Level of evidence: $B$

- Experts opinion: completely agree (67\%), mostly agree (33\%), partially agree (0\%), mostly disagree (0\%) and completely disagree (0\%).

\section{Swallowing and diet}

Statements \#21: NPC patients should undergo a comprehensive swallowing assessment by a speech and language therapist and nutritional review by a dietician. Instruction in dietary modification and compensatory postures may be beneficial for individuals with dysphagia. The family should be educated regarding the likely eventual need for assisted feeding, as part of an ongoing process.

- Strength of recommendation: 1

- Level of evidence: $B$
- Experts opinion: completely agree (86\%), mostly agree (14\%), partially agree (0\%), mostly disagree (0\%) and completely disagree (0\%).

Speech

Statements \#22: NPC patients should undergo a comprehensive communication evaluation by a speech and language therapist and receive appropriate treatment.

- Strength of recommendation: 1

- Level of evidence: $B$

- Experts opinion: completely agree (87\%), mostly agree (7\%), partially agree (7\%), mostly disagree (0\%) and completely disagree (0\%).

\section{Spasticity}

Statements \#23: Individuals with NPC may benefit from assessments for spasticity and incipient or established contracture. Spasticity and spasms should be treated at an early stage, initially by non-pharmacological means. If these are unsuccessful, pharmacological agents including Baclofen, Tizanidine, Benzodiazepines, Dantrolene sodium and botulinum toxin injections may be considered.

- Strength of recommendation: 1

- Level of evidence: $B$ 
- Experts opinion: completely agree (93\%), mostly agree (7\%), partially agree (0\%), mostly disagree (0\%) and completely disagree (0\%).

\section{Bowel dysfunction}

Statements \#24: Consider modifying diet and lifestyle to optimize stool consistency and avoid faecal impaction and incontinence. If required, consider appropriate laxatives to optimize gut transit and stool consistency.

- Strength of recommendation: 1

- Level of evidence: $B$

- Experts opinion: completely agree (80\%), mostly agree (20\%), partially agree (0\%), mostly disagree (0\%) and completely disagree (0\%).

\section{Bladder dysfunction}

Statements \#25: Individuals with NPC should have their history reviewed for symptoms suggestive of neurogenic bladder (recurrent urinary tract infection, nocturia, incomplete evacuation, dribbling) and be referred for urologic evaluation if symptoms are present.

- Strength of recommendation: 1

- Level of evidence: $B$

- Experts opinion: completely agree (79\%), mostly agree (21\%), partially agree (0\%), mostly disagree (0\%) and completely disagree (0\%).

\section{Cataplexy and seizures}

Statements \#26: Cataplexy and seizures are common manifestations of NPC and their early recognition is important and should be managed promptly as per local/ national management guidelines. Protriptyline, other tricyclic agents or modafanil have been efficacious for cataplexy. Epilepsy should be treated by a neurologist aware of the disease (possibility of aggravation with antiepileptic drugs like carbamazepine and vigabatrin should be considered).

- Strength of recommendation: 1

- Level of evidence: $B$

- Experts opinion: completely agree (62\%), mostly agree (38\%), partially agree (0\%), mostly disagree (0\%) and completely disagree (0\%).

\section{Cognitive decline}

Statements \#27: Individuals with NPC benefit from regular evaluation of their cognitive function and consideration should be given to changes in their cognitive ability that may impact on independence/school/work and daily living activities. Testing should be age and functionally appropriate, using standardised assessment tools. Strategies to ensure the safety of the patient's environment and the availability of support mechanisms are essential to improve the quality of life of the patient.

- Strength of recommendation: 1

- Level of evidence: $B$

- Experts opinion: completely agree (80\%), mostly agree (13\%), partially agree (7\%), mostly disagree (0\%) and completely disagree (0\%).

\section{Mental wellbeing}

Statements \#28: Clinicians, caregivers and individuals with NPC should be aware that there is an increased prevalence of behavioural problems and other psychiatric disorders such as anxiety, depression or psychosis in NPC. There should be a low threshold for referral to a clinical psychology/psychiatric team as appropriate, and for the use of both non-pharmacological and/or pharmacological treatments.

- Strength of recommendation: 1

- Level of evidence: $B$

- Experts opinion: completely agree (93\%), mostly agree (7\%), partially agree (0\%), mostly disagree (0\%) and completely disagree (0\%).

\section{Hypersalivation / drooling}

Statements \#29: Individuals with NPC are at increased risk of hypersalivation/drooling and should be treated with established interventions including postural drainage +/-pharmacological agents such as Hyoscine hydrobromide transdermal patches; Glycopyrronium orally, subcutaneously or via a gastrostomy and small doses of orally administered atropine, or parotid/submandibular glandular injections of botulinum toxin.

- Strength of recommendation: 1

- Level of evidence: $B$

- Experts opinion: completely agree (73\%), mostly agree (27\%), partially agree (0\%), mostly disagree (0\%) and completely disagree (0\%).

\section{Hearing}

Statements \#30: Individuals with NPC should undergo a comprehensive hearing assessment at the time of diagnosis and thereafter annually. When appropriate, patients should be offered hearing devices to improve general communication.

- Strength of recommendation: 1

- Level of evidence: $B$

- Experts opinion: completely agree (67\%), mostly agree (20\%), partially agree (13\%), mostly disagree (0\%) and completely disagree (0\%). 


\section{Disease modifying therapy \\ Miglustat}

Miglustat, a substrate reduction therapy, is the only licensed disease modifying medicine in the European Union for the treatment of neurological manifestations of patients with NPC disease. In some patients, miglustat has been shown to halt or attenuate disease progression $[60,61]$.

Miglustat start criteria Statement \# 31: All patients with a confirmed diagnosis of NPC should be considered for miglustat therapy

- Strength of recommendation: 2

- Level of evidence: $C$

- Experts opinion: completely agree (13\%), mostly agree (38\%), partially agree (13\%), mostly disagree (25\%) and completely disagree (13\%).

To understand the effects of disease modifying therapy in NPC, information about the natural history of disease progression is required. In one natural history of NPC, a cohort of 57 NPC patients was analysed, with $85.7 \%$ who were followed up for more than 1 year showed neurological disease progression [62]. In this cohort were children $<6$ years who had normal evaluation suggesting they might have had a late onset phenotype. The rate of progression was 0.12 points per year (CI 0.09 to 0.15 ) using a composite NPC scoring system where the maximum score of 4 indicates severe disease. The rates of progression correlated with age at diagnosis, the younger patients showing the greatest progression of disease.

A phase I/II study of miglustat was performed in 29 patients $\geq 12$ years of age with proven NPC [61] Patients were randomised 2:1 to receive miglustat $200 \mathrm{mg}$ tds or standard care for 1 year, with the option for adult patients to enrol into a further 1 year extension study to receive active drug. A further subgroup of 12 patients $\leq 12$ years received miglustat at a dose based on body surface area. The study included male and female patients with NPC confirmed by cholesterol esterification and abnormal filipin staining, able to safely ingest a capsule, with normal renal function and not suffering from clinically significant diarrhoea. Patients with other medical conditions or were on concomitant medications that would render them unsuitable for the study were excluded. Patients were assessed for the primary end point - change in horizontal saccadic eye movements (HSEM) at baseline and at 12 months. At each assessment of eye movement velocity was tested twice during a $24 \mathrm{~h}$ period. Swallowing ability was assessed at screening, 6 months and 12 months. Neurological assessments and quality of life assessments were performed at screening, 3, 6, 9 and 12 months.
Treatment with Miglustat resulted in improvements in the primary end point (HSEM) compared with standard care. At 12 months, HSEM velocity had improved in patients treated with miglustat versus those receiving standard care; results were significant when patients taking benzodiazepines were excluded $(p=0.028)$. Children showed an improvement in HSEM velocity of similar magnitude at 12 months. Improvement in swallowing capacity, stable auditory acuity, and a slower deterioration in ambulatory index were also seen in treated patients older than 12 years. Safety assessments were performed at screening every 3 months and at post screening follow up. Adverse events (AEs) were recorded at each post-screening visit. The most frequently occurring AEs were diarrhoea (85\%), flatulence (70\%), and weight loss (65\%). Discontinuation was reported in one paediatric patient due to memory impairment and in one adult patient due to confusional state and in one other adult patient due to diarrhoea. No deaths were reported. The study concluded that Miglustat was safe and improved or stabilised several clinically relevant markers of NPC [61]. This is the first agent studied in NPC for which there is both animal and clinical data supporting a disease modifying benefit.

Longer term (24 month) data of patients in the above study, as part of an open label extension has been reported [63]. 19/29 patients from the pivotal study completed the two-year study of whom 15/19 completed 24 months of miglustat therapy. The 24-month data did not meet the primary end point of improvement in HSEM velocity. Small patient numbers produced wide confidence intervals making the data unreliable; however a modest deterioration in HSEM velocity was noted. Overall there was stabilisation of neurological symptoms (cognition, ambulation and swallow) in $68 \%$ of this group with a trend towards improvement when compared to the natural history data.

Statement \#32: NPC patients who are pre-symptomatic or have only spleen/liver enlargement should not be offered miglustat.

- Strength of recommendation 2

- Level of evidence C

- Experts opinion: completely agree (27\%), mostly agree (40\%), partially agree (27\%), mostly disagree (7\%) and completely disagree (0\%).

All pre-symptomatic subjects should undergo regular evaluation by a neurologist and/or metabolic physician, so that treatment can be considered at an early onset of neurological manifestation.

Statement \#33: Miglustat should not be started in NPC patients with advanced neurological disease/dementia.

- Strength of recommendation 2

- Level of evidence $C$ 
- Experts opinion: completely agree (47\%), mostly agree (33\%), partially agree (20\%), mostly disagree (0\%) and completely disagree (0\%).

Currently there are limited data on patients with NPC with advanced neurological disease being commenced on miglustat. Based on the French experience of miglustat treatment in 20 children the NPC disability scores improved or stabilized in $75 \%$ of the patients with lateinfantile onset disease (onset of symptoms $<5$ years of age) but no patients with the early infantile onset form (onset of symptoms $<1$ year of age) had a good neurological outcome [64]. Only one patient out of 9 children treated before 4 years of age demonstrated stabilisation. More data are needed to determine of the efficacy of miglustat in patients below the age of 4 years.

Miglustat therapy is NOT appropriate for patients who have profound neurological disease, which, in the opinion of the attending physician, would make it difficult to assess for any improvements with therapy. Such symptoms may include but are not limited to:

a. Profound dementia resulting in the need for $24 \mathrm{~h}$ care

b. Inability to ambulate without a wheelchair

c. Complete lack of verbal communication

d. Swallowing difficulties profound enough to require tube feeding through a per-cutaneous gastrostomy

Statement \#34: Miglustat should not be started in NPC patients with another life threatening illness with estimated life span less than 1 year.

- Strength of recommendation 2

- Level of evidence $C$

- Experts opinion: completely agree (73\%), mostly agree (20\%), partially agree (7\%), mostly disagree (0\%) and completely disagree (0\%).

Whilst there is no evidence in the literature to assess this, most guidelines for other new therapies such as enzyme replacement therapies, and some national guidelines specify the above as an exclusion criteria $[65,66]$.

\section{Experimental therapies}

Clinical trials testing the safety and efficacy of intrathecal [67] or intravenous preparations of 2-hydroxypropyl- $\beta$ cyclodextrin and oral Arimoclomol are ongoing. Although the disease is a disorder of cholesterol trafficking, cholesterol-lowering drugs have not been shown to be effective at altering the course of the disease $[68,69]$. In addition, a number of other therapeutic modalities in animal and early phase human studies are underway.
Follow up, transition, advanced care planning and genetic issues

Follow up

Statements \#35: NPC is a progressive condition and patients require regular follow up. Treatment goals should be established at diagnosis and reviewed regularly, aimed at improving or maintaining the physical and psychosocial wellbeing of individuals with NPC and their families.

- Strength of recommendation: 1

- Level of evidence: $B$

- Experts opinion: completely agree (88\%), mostly agree (6\%), partially agree (6\%), mostly disagree (0\%) and completely disagree (0\%).

\section{Transition}

Statements \#36: Most children with late-infantile and juvenile onset NPC are expected to reach adulthood with complex medical and psychosocial needs. The process of transition from paediatric to adult services should begin early and must include appropriate services in the community to provide a seamless transition from childhood to adult life. Individuals with NPC may benefit from a detailed assessment identifying barriers to independence.

- Strength of recommendation: 1

- Level of evidence: $B$

- Experts opinion: completely agree (88\%), mostly agree $(13 \%)$, partially agree $(0 \%)$, mostly disagree (0\%) and completely disagree (0\%).

\section{Advance care planning}

Statements \#37: Specialist centre care providers, family physician/paediatrician and local palliative care services should develop close working links to support individuals and families with NPC through the lifespan, including: a) advance care planning with regular updating. b) proper flow of communication and information for patients and their families, c) a designated point of contact for each stage in their care pathway. An individual identified as being near the end- of-life may benefit from ongoing access to palliative care services including for symptom control, respite, psychological and spiritual support.

- Strength of recommendation: 1

- Level of evidence: $B$

- Experts opinion: completely agree (94\%), mostly agree (6\%), partially agree (0\%), mostly disagree (0\%) and completely disagree (0\%).

\section{Genetic issues}

Statements \#38: Requests for NPC pre-symptomatic genetic testing are best managed on a case-by-case basis. Pre-symptomatic testing in minors is not permitted in 
some jurisdictions, and in any case, the risks and benefits from the perspectives of both the child and parents should be carefully discussed in the context of formal counselling from a suitably qualified individual. All patients identified pre-symptomatically should be referred to specialist centres for surveillance and early detection of neurological manifestations.

- Strength of recommendation: 2

- Level of evidence: $B$

- Experts opinion: completely agree (81\%), mostly agree (6\%), partially agree (13\%), mostly disagree (0\%) and completely disagree (0\%).

Statements \#39: Prenatal testing for NPC should be offered to all at risk couples and requires careful counselling by clinical geneticists and NPC specialists. Molecular genetic analysis of chorionic villus samples is the strategy of choice, based on mutations identified in the family.

- Strength of recommendation: 1

- Level of evidence: $B$

- Experts opinion: completely agree (75\%), mostly agree (13\%), partially agree (6\%), mostly disagree (6\%) and completely disagree (0\%).

\section{Conclusion}

These guidelines are the result of an international collaboration of experts in the care of NPC and the evidence gathered to write these guidelines is the best evidence available to the experts. These guidelines address the management of children and adults affected by NPC and are intended to facilitate optimal care to all NPC patients regardless of their demography and access to health care. In addition, it defines standard of care against which practice can be audited and best practice can be spread. The Guidelines Working Group commits itself to revise this work in 5 years' time to reflect new data pertaining to future research findings and new therapies.

\footnotetext{
Abbreviations

7-KC: 7-ketocholesterol; AE: Adverse Event; AGREE II: Appraisal of Guidelines for Research \& Evaluation; ASMD: Acid Sphingomyelinase Deficiency; CHAFEA: Consumers, Health, Agriculture and Food Executive Agency; Ctriol: Cholestane-3ß, 5a, 6ß-triol; DG-SANGO: EU Directorate General for Health and Consumers; GDG: Guidelines Development Group; GRADE: Grading of Recommendations, Assessment, Development and Evaluations; HSEM: Horizontal Saccadic Eye Movements; INPDA: International Niemann-Pick Disease Alliance; INPDR: International Niemann-Pick Disease Registry; Iyso-SM 509: Lyso-sphingomyelin 509; MetabERN: European Metabolic Reference network; MRI: Magnetic Resonance Imaging; NPC: Niemann-Pick Type C; RCT: Randomized Controlled Trials; VSGP: Vertical supranuclear gaze palsy
}

\section{Acknowledgments}

This work was initiated by the International Niemann-Pick Disease Alliance (INPDA) and financially supported by the EU Directorate General for Health and Consumers via the Consumers, Health, Agriculture and Food Executive Agency (grant number 2012120 NPDR). The members of the guideline development group would like to thank all the INPDR partners and their institutions (University Hospitals Birmingham NHS Foundation Trust, International Niemann-Pick Disease Alliance, Niemann-Pick UK and University College London, United Kingdom; Azienda Ospedaliero Universitaria "Santa Maria della Misericordia", Italy; Children's University Hospital, Ireland; Fundacio Privada Clinic per a la Recerca Biomedica and Fundaction Niemann-Pick de Espana, Spain; Niemann-Pick Selbsthilfegruppe and Universitatsklinikum Heidelberg, Germany; University Karlova v Praze, Czech Republic and Assistance-Publique Hôpitaux de Paris, France) for their co-funding of the INPDR programme and support in the development of these guidelines.

\section{Funding}

This publication arises from the project 'International Niemann-Pick Disease Registry' which has received funding from the European Union, in the framework of the Health Programme.

\section{Availability of data and materials}

Data sharing not applicable to this article as no datasets were generated or analysed during the current study.

\section{Authors' contributions}

All authors have contributed to the guidelines development process of planning, writing and revising of the manuscript. All authors read and approved the final manuscript.

\section{Ethics approval and consent to participate}

Not applicable.

\section{Consent for publication \\ Not applicable.}

\section{Competing interests}

$A D, B B, T H, Y N, S J, M W, D O, S S, P G, M S, U R, M T V$ and MP has received travel grant from Actelion. Shire has provided funding to YN, SJ, SS, MTV, AD, BB, $\mathrm{MH}$ and MP. Genzyme has provided funding to YN, SJ, SS, Jl, MH and MP. Orphazyme has provided funding to $\mathrm{Jl}, \mathrm{AD}$ and BB. Alexion has provided funding to SS and MP. Vtesse has provided travel grants to MTV and MP. SS has received funding from Biomarin and Pfizer. MP has received funding from Agio, Amicus and Novartis. SJ has received funding from Biomarin, Ultragenyx, PTC and Orchard Theraputics.

\section{Publisher's Note}

Springer Nature remains neutral with regard to jurisdictional claims in published maps and institutional affiliations.

\section{Author details}

${ }^{1}$ Institute of Metabolism and System Research, University of Birmingham, Birmingham, UK. ${ }^{2}$ AMC Hospital of Udine, Udine, Italy. ${ }^{3}$ Royal Free London. NHS Foundation Trust, London, UK. ${ }^{4}$ Vancouver General Hospital, Vancouver, Canada. ${ }^{5}$ Hospital Sant Joan de Deu, Barcelona, Spain. ${ }^{6}$ INSERM U820, Université de Lyon, Faculté de Médecine Lyon-Est, Lyon 69372, France. ${ }^{7}$ Royal Melbourne Hospital, Parkville, Australia. ${ }^{8}$ University Hospitals Birmingham NHS Foundation Trust, Birmingham, UK. ${ }^{9}$ Department of Pediatric Neurology, Reference Center of Lysosomal Diseases, Trousseau Hospital, APHP, GRC ConCer-LD, Sorbonne Universities, UPMC University 06, Paris, France. ${ }^{10}$ Universitatsklinikum Tubingen Institut fur Medizinische Genetik undangewandte Genomik, Tubingen, Germany. ${ }^{11}$ Niemann-Pick UK, Washington, UK. ${ }^{12}$ Salford Royal NHS Foundation Trust, Salford, UK. ${ }^{13}$ MRC Laboratory for Molecular Cell Biology, London, UK. ${ }^{14}$ Children's University Hospital, Dublin, Republic of Ireland. ${ }^{15} \mathrm{Hospital}$ Clinic de Barcelona, Barcelona, Spain. ${ }^{16} \mathrm{Hopital}$ Universitaire Pitie Salpetriere, Paris, France. ${ }^{17}$ Universitatsklinikum Regensburg Klinik und Poliklinik fur Chirurgie, Regensburg, Germany. ${ }^{18}$ Universitatmedizin Mainz, Mainz, Germany. ${ }^{19} \mathrm{Charlies}$ University in Prague, Prague, Czech Republic. ${ }^{20} \mathrm{Central}$ Manchester University Hospitals NHS Foundation Trust, Manchester, UK. ${ }^{21}$ University of Washington School of Medicine, Seattle, USA. ${ }^{22}$ Mayo 1290 Clinic Department of Pediatric and Adolescent Medicine, Minnesota, USA.
} 


\section{Received: 24 November 2017 Accepted: 13 March 2018} Published online: 06 April 2018

\section{References}

1. Brouwers MC, Kho ME, Bowman GP, et al. AGREE II: advanced guideline development, reporting and evaluation in health care. CMAJ. 2010;182: E839-42.

2. Vanier MT, Duthel S, Rodriguez-Lafrasse C, Pentchev P, Carstea ED. Genetic heterogeneity in Niemann-Pick C disease: a study using somatic cell hybridization and linkage analysis. Am J Hum Genet. 1996;58:118-25.

3. Carstea ED, Morris JA, Coleman KG, et al. Niemann-Pick C1 disease gene: homology to mediators of cholesterol homeostasis. Science. 1997;277:228-31.

4. Naureckiene $\mathrm{S}$, Sleat DE, Lackland $\mathrm{H}$, et al. Identification of HE1 as the second gene of Niemann-Pick C disease. Science. 2000;290:2298-301.

5. Neufeld EB, Wastney M, Patel S, et al. The Niemann-Pick C1 protein resides in a vesicular compartment linked to retrograde transport of multiple lysosomal cargo. J Biol Chem. 1999;274:9627-35.

6. Friedland N, Liou HL, Lobel P, Stock AM. Structure of a cholesterol-binding protein deficient in Niemann-Pick type C2 disease. Proc Natl Acad Sci U S A. 2003;100:2512-7.

7. Kwon HJ, Abi-Mosleh L, Wang ML, et al. Structure of N-terminal domain of NPC1 reveals distinct subdomains for binding and transfer of cholesterol. Cell. 2009;137:1213-24.

8. Vanier MT. Complex lipid trafficking in Niemann-Pick disease type C. J Inherit Metab Dis. 2015;38:187-99.

9. Imrie J, Dasgupta S, Besley GT, et al. The natural history of Niemann-Pick disease type C in the UK. J Inherit Metab Dis. 2007;30:51-9.

10. Spiegel R, Raas-Rothschild A, Reish O, et al. The clinical spectrum of fetal Niemann-Pick type C. Am J Med Genet A. 2009;149A:446-50.

11. Vanier MT. Niemann-Pick disease type C. Orphanet J Rare Dis. 2010;5:16.

12. Jahnova $H$, Dvorakova L, Vlaskova $H$, et al. Observational, retrospective study of a large cohort of patients with Niemann-Pick disease type $C$ in the Czech Republic: a surprisingly stable diagnostic rate spanning almost 40 years. Orphanet J Rare Dis. 2014;9:140.

13. Imrie J, Heptinstall L, Knight S, Strong K. Observational cohort study of the natural history of Niemann-Pick disease type $C$ in the UK: a 5-year update from the UK clinical database. BMC Neurol. 2015;15:257.

14. Meikle PJ, Hopwood JJ, Clague AE, Carey WF. Prevalence of lysosomal storage disorders. JAMA. 1999;281:249-54.

15. Poorthuis BJ, Wevers RA, Kleijer WJ, et al. The frequency of lysosomal storage diseases in the Netherlands. Hum Genet. 1999;105:151-6.

16. Pinto $\mathrm{R}$, Caseiro $\mathrm{C}$, Lemos $\mathrm{M}$, et al. Prevalence of lysosomal storage diseases in Portugal. Eur J Hum Genet. 2004;12:87-92.

17. Poupetova H, Ledvinova J, Berna L, Dvorakova L, Kozich V, Elleder M. The birth prevalence of lysosomal storage disorders in the Czech Republic: comparison with data in different populations. J Inherit Metab Dis. 2010;33: 387-96.

18. Al-Jasmi FA, Tawfig N, Berniah A, et al. Prevalence and novel mutations of Lysosomal storage disorders in United Arab Emirates : LSD in UAE. JIMD Rep. 2013;10:1-9.

19. Wassif CA, Cross JL, Iben J, et al. High incidence of unrecognized visceral/ neurological late-onset Niemann-Pick disease, type C1, predicted by analysis of massively parallel sequencing data sets. Genet Med. 2016;18:41-8.

20. Patterson MC, Mengel E, Wijburg FA, et al. Disease and patient characteristics in NP-C patients: findings from an international disease registry. Orphanet J Rare Dis. 2013;8:12.

21. Trendelenburg G, Vanier MT, Maza S, et al. Niemann-Pick type $C$ disease in a 68-year-old patient. J Neurol Neurosurg Psychiatry. 2006;77:997-8.

22. Stampfer $M$, Theiss S, Amraoui $Y$, et al. Niemann-Pick disease type C clinical database: cognitive and coordination deficits are early disease indicators. Orphanet J Rare Dis. 2013;8:35.

23. Garver WS, Francis GA, Jelinek D, et al. The national Niemann-Pick C1 disease database: report of clinical features and health problems. Am J Med Genet A. 2007;143A:1204-11.

24. Pineda M, Perez-Poyato MS, O'Callaghan M, et al. Clinical experience with miglustat therapy in pediatric patients with Niemann-Pick disease type C: a case series. Mol Genet Metab. 2010;99:358-66.

25. Schicks J, Muller Vom Hagen J, Bauer $P$, et al. Niemann-Pick type $C$ is frequent in adult ataxia with cognitive decline and vertical gaze palsy. Neurology. 2013; https://doi.org/10.1212/WNL.0b013e31828869f9.
26. Abela L, Plecko B, Palla A, et al. Early co-occurrence of a neurologicpsychiatric disease pattern in Niemann-Pick type $C$ disease: a retrospective Swiss cohort study. Orphanet J Rare Dis. 2014;9:176.

27. Sévin $M$, Lesca $G$, Baumann $N$, et al. The adult form of Niemann-Pick disease type C. Brain. 2007;130:120-33.

28. Mengel $\mathrm{E}$, Klünemann $\mathrm{HH}$, Lourenço $\mathrm{CM}$, et al. Niemann-Pick disease type $\mathrm{C}$ symptomatology: an expert-based clinical description. Orphanet J Rare Dis. 2013;8:166.

29. Walterfang M, Fietz M, Fahey $M$, et al. The neuropsychiatry of NiemannPick type C disease in adulthood. J Neuropsychiatry Clin Neurosci. 2006; 18:158-70.

30. Kheder A, Scott C, Olpin S, Hadjivassiliou M. Niemann-Pick type C: a potentially treatable disorder? Pract Neurol. 2013;13:382-5.

31. Wijburg FA, Sedel F, Pineda M, et al. Development of a suspicion index to aid diagnosis of Niemann-Pick disease type C. Neurology. 2012;78:1560-7.

32. Yanjanin NM, Velez II, Gropman A, et al. Linear clinical progression, independent of age of onset, in Niemann-Pick disease, type C. Am J Med Genet B Neuropsychiatr Genet. 2010;153B:132-40.

33. Abel LA, Walterfang M, Fietz M, Bowman EA, Velakoulis D. Saccades in adult Niemann-Pick disease type $C$ reflect frontal, brainstem, and biochemical deficits. Neurology. 2009;72:1083-6.

34. Abel LA, Bowman EA, Velakoulis D, et al. Saccadic eye movement characteristics in adult Niemann-Pick type C disease: relationships with disease severity and brain structural measures. PLoS One. 2012;7:e50947.

35. Vanier MT, Gissen $P$, Bauer $P$, et al. Diagnostic tests for Niemann-Pick disease type C (NP-C): a critical review. Mol Genet Metab. 2016;118:244-54.

36. Patterson M, Clayton P, Gissen P, Anheim M, Bauer P, Bonnot O, et al. Recommendations for the detection and diagnosis of Niemann-Pick disease type C. Neurol Clin Pract. 2017;7(6):499-511.

37. Porter FD, Scherrer DE, Lanier MH, et al. Cholesterol oxidation products are sensitive and specific blood-based biomarkers for Niemann-Pick C1 disease. Sci Transl Med. 2010;2:56ra81.

38. Jiang X, Sidhu R, Porter FD, et al. A sensitive and specific LC-MS/MS method for rapid diagnosis of Niemann-Pick C1 disease from human plasma. J Lipid Res. 2011;52:1435-45.

39. Welford RW, Garzotti M, Lourenço C, et al. Plasma lysosphingomyelin demonstrates great potential as a diagnostic biomarker for Niemann-Pick disease type C in a retrospective study. PLoS One. 2014;9:e114669.

40. Giese AK, Mascher H, Grittner U, et al. A novel, highly sensitive and specific biomarker for Niemann-Pick type C1 disease. Orphanet J Rare Dis. 2015:10:78.

41. Kuchar L, Sikora J, Gulinello ME, et al. Quantitation of plasmatic lysosphingomyelin and lysosphingomyelin-509 for differential screening of Niemann-Pick a/B and C diseases. Anal Biochem. 2017;525:73-7.

42. Pettazzoni M, Froissart R, Pagan C, et al. LC-MS/MS multiplex analysis of lysosphingolipids in plasma and amniotic fluid: a novel tool for the screening of sphingolipidoses and Niemann-Pick type C disease. PLoS One. 2017;12:e0181700.

43. Polo G, Burlina AP, Kolamunnage TB, et al. Diagnosis of sphingolipidoses: a new simultaneous measurement of lysosphingolipids by LC-MS/MS. Clin Chem Lab Med. 2017;55:403-14.

44. Voorink-Moret M, Goorden SMI, van Kuilenburg, A B P, Wijburg FA, Ghauharali-van der Vlugt, J M M, Beers-Stet FS, et al. Rapid screening for lipid storage disorders using biochemical markers. Expert center data and review of the literature. Mol Genet Metab. 2018;123(2):76-84.

45. Jiang X, Sidhu R, Mydock-McGrane L, et al. Development of a bile acidbased newborn screen for Niemann-Pick disease type C. Sci Transl Med. 2016:8:337ra63.

46. Mazzacuva F, Mills P, Mills $K$, et al. Identification of novel bile acids as biomarkers for the early diagnosis of Niemann-Pick $C$ disease. FEBS Lett. 2016:590:1651-62

47. Patterson MC, Hendriksz CJ, Walterfang M, Sedel F, Vanier MT, Wijburg F. Recommendations for the diagnosis and management of Niemann-Pick disease type C: an update. Mol Genet Metab. 2012;106:330-44.

48. Millat G, Marcais C, Rafi MA, et al. Niemann-Pick C1 disease: the 11061T substitution is a frequent mutant allele in patients of western European descent and correlates with a classic juvenile phenotype. Am J Hum Genet. 1999;65:1321-9.

49. Gelsthorpe ME, Baumann N, Millard E, et al. Niemann-Pick type C1 I1061T mutant encodes a functional protein that is selected for endoplasmic reticulum-associated degradation due to protein misfolding. J Biol Chem. 2008;283:8229-36 
50. Millat G, Marçais C, Tomasetto C, et al. Niemann-Pick C1 disease: correlations between NPC1 mutations, levels of NPC1 protein, and phenotypes emphasize the functional significance of the putative sterol-sensing domain and of the cysteine-rich luminal loop. Am J Hum Genet. 2001;68:1373-85.

51. Vanier MT, Latour P. Laboratory diagnosis of Niemann-Pick disease type C: the filipin staining test. Methods Cell Biol. 2015;126:357-75.

52. Reunert J, Fobker M, Kannenberg F, et al. Rapid diagnosis of 83 patients with Niemann-Pick type C disease and related cholesterol transport disorders by Cholestantriol screening. EBioMed. 2016;4:170-5.

53. Romanello M, Zampieri S, Bortolotti N, et al. Comprehensive evaluation of plasma 7-ketocholesterol and cholestan-3beta,5alpha,6beta-triol in an Italian cohort of patients affected by Niemann-Pick disease due to NPC1 and SMPD1 mutations. Clin Chim Acta. 2016:455:39-45.

54. Walterfang M, Abel LA, Desmond P, Fahey MC, Bowman EA, Velakoulis D. Cerebellar volume correlates with saccadic gain and ataxia in adult Niemann-Pick type C. Mol Genet Metab. 2013;108:85-9.

55. Walterfang $M$, Patenaude $B$, Abel $L A$, et al. Subcortical volumetric reductions in adult Niemann-Pick disease type C: a cross-sectional study. AJNR Am J Neuroradiol. 2013;34:1334-40.

56. Walterfang $M$, Fahey $M$, Desmond $P$, et al. White and gray matter alterations in adults with Niemann-Pick disease type C: a cross-sectional study. Neurology. 2010;75:49-56.

57. Walterfang $M$, Fahey $M$, Abel $L$, et al. Size and shape of the corpus callosum in adult Niemann-Pick type $C$ reflects state and trait illness variables. AJNR Am J Neuroradiol. 2011;32:1340-6.

58. Walterfang M, Macfarlane MD, Looi JC, et al. Pontine-to-midbrain ratio indexes ocular-motor function and illness stage in adult Niemann-Pick disease type C. Eur J Neurol. 2011;19:462-7.

59. Chiba Y, Komori H, Takei S, Hasegawa-Ishii S, Kawamura N, Adachi K, et al. Niemann-Pick disease type C1 predominantly involving the frontotemporal region, with cortical and brainstem Lewy bodies: An autopsy case. Neuropathology. 2014;34(1):49-57.

60. Patterson MC, Mengel E, Vanier MT, et al. Stable or improved neurological manifestations during miglustat therapy in patients from the international disease registry for Niemann-Pick disease type C: an observational cohort study. Orphanet J Rare Dis. 2015;10:65.

61. Patterson MC, Vecchio D, Prady H, Abel L, Wraith JE. Miglustat for treatment of Niemann-Pick C disease: a randomised controlled study. Lancet Neurol. 2007;6:765-72.

62. Wraith JE, Guffon N, Rohrbach M, et al. Natural history of Niemann-Pick disease type $\mathrm{C}$ in a multicentre observational retrospective cohort study. Mol Genet Metab. 2009;98:250-4

63. Wraith JE, Vecchio D, Jacklin E, et al. Miglustat in adult and juvenile patients with Niemann-Pick disease type C: long-term data from a clinical trial. Mol Genet Metab. 2010;99:351-7.

64. Héron B, Valayannopoulos V, Baruteau J, et al. Miglustat therapy in the French cohort of paediatric patients with Niemann-Pick disease type C. Orphanet J Rare Dis. 2012;7:36.

65. Melancon S, Clarke J, Sirrs S, Prasad C, Mackrell M, Maranda B, et al. Niemann-Pick type C (NPC): Canadian Management Guidelines. 2015; Available at: http://www.garrod.ca/wp-content/uploads/NPC-CanadianGuidelines-June-5-2015.pdf.

66. Biegstraaten M, Arngrimsson R, Barbey F, et al. Recommendations for initiation and cessation of enzyme replacement therapy in patients with Fabry disease: the European Fabry working group consensus document. Orphanet J Rare Dis. 2015;10:3.

67. Ory DS, Ottinger EA, Farhat NY, et al. Intrathecal 2-hydroxypropyl-betacyclodextrin decreases neurological disease progression in Niemann-Pick disease, type C1: a non-randomised, open-label, phase 1-2 trial. Lancet. 2017;390:1758-68.

68. Patterson MC, Di Bisceglie AM, Higgins JJ, et al. The effect of cholesterollowering agents on hepatic and plasma cholesterol in Niemann-Pick disease type C. Neurology. 1993;43:61-4.

69. Schiffmann R. Niemann-Pick disease type C. From bench to bedside. JAMA. 1996;276:56

70. Vanier MT, Rodriguez-Lafrasse C, Rousson R, et al. Type C Niemann-Pick disease: biochemical aspects and phenotypic heterogeneity. Dev Neurosci. 1991;13:307-14.

71. Fernandez-Valero EM, Ballart A, Iturriaga C, et al. Identification of 25 new mutations in 40 unrelated Spanish Niemann-Pick type $C$ patients: genotypephenotype correlations. Clin Genet. 2005;68:245-54.
72. Macias-Vidal J, Gort L, Lluch M, Pineda M, Coll MJ. Nonsense-mediated mRNA decay process in nine alleles of Niemann-Pick type $C$ patients from Spain. Mol Genet Metab. 2009;97:60-4.

73. Macias-Vidal J, Rodriguez-Pascau L, Sanchez-Olle G, et al. Molecular analysis of 30 Niemann-Pick type C patients from Spain. Clin Genet. 2011;80:39-49.

74. Tarugi $P$, Ballarini $G$, Bembi B, et al. Niemann-Pick type $C$ disease: mutations of NPC1 gene and evidence of abnormal expression of some mutant alleles in fibroblasts. J Lipid Res. 2002;43:1908-19.

75. Fancello T, Dardis A, Rosano C, et al. Molecular analysis of NPC1 and NPC2 gene in 34 Niemann-Pick C Italian patients: identification and structural modeling of novel mutations. Neurogenetics. 2009;10:229-39.

76. Wraith JE, Baumgartner MR, Bembi B, et al. Recommendations on the diagnosis and management of Niemann-Pick disease type C. Mol Genet Metab. 2009;98:152-65.

77. Miao N, Lu X, O'Grady NP, Yanjanin N, Porter FD, Quezado ZM. NiemannPick disease type C: implications for sedation and anesthesia for diagnostic procedures. J Child Neurol. 2012;27:1541-6.

78. Shin J, Epperson K, Yanjanin NM, et al. Defining natural history: assessment of the ability of college students to aid in characterizing clinical progression of Niemann-Pick disease, type C. PLoS One. 2011;6:e23666.

79. Bonnot O, Klünemann HH, Sedel F, Tordjman S, Cohen D, Walterfang M. Diagnostic and treatment implications of psychosis secondary to treatable metabolic disorders in adults: a systematic review. Orphanet J Rare Dis. 2014;9:65.

80. Klarner B, Klünemann HH, Lurding R, Aslanidis C, Rupprecht R. Neuropsychological profile of adult patients with Niemann-Pick C1 (NPC1) mutations. J Inherit Metab Dis. 2007;30:60-7.

81. King KA, Gordon-Salant S, Yanjanin N, et al. Auditory phenotype of Niemann-Pick disease, type C1. Ear Hear. 2014;35:110-7.

82. Fecarotta S, Amitrano M, Romano A, et al. The videofluoroscopic swallowing study shows a sustained improvement of dysphagia in children with Niemann-Pick disease type C after therapy with miglustat. Am J Med Genet A. 2011;155A:540-7.

83. Galanaud D, Tourbah A, Lehericy S, et al. 24 month-treatment with miglustat of three patients with Niemann-Pick disease type C: follow up using brain spectroscopy. Mol Genet Metab. 2009;96:55-8.

84. Scheel M, Abegg M, Lanyon LJ, Mattman A, Barton JJ. Eye movement and diffusion tensor imaging analysis of treatment effects in a Niemann-Pick Type C patient. Mol Genet Metab. 2010;99(3):291-95.

85. Sedel F, Chabrol B, Audoin B, et al. Normalisation of brain spectroscopy findings in Niemann-Pick disease type $C$ patients treated with miglustat. I Neurol. 2016;263:927-36.

\section{Submit your next manuscript to BioMed Central and we will help you at every step:}

- We accept pre-submission inquiries

- Our selector tool helps you to find the most relevant journal

- We provide round the clock customer support

- Convenient online submission

- Thorough peer review

- Inclusion in PubMed and all major indexing services

- Maximum visibility for your research

Submit your manuscript at www.biomedcentral.com/submit 